Wasting and stunting - similarities and differences

Policy and programmatic implications

Briend, André; Khara, Tanya; Dolan, Carmel

Published in:

Food and Nutrition Bulletin

DOI:

$10.1177 / 15648265150361 S 103$

Publication date:

2015

Document version

Publisher's PDF, also known as Version of record

Document license:

CC BY

Citation for published version (APA):

Briend, A., Khara, T., \& Dolan, C. (2015). Wasting and stunting - similarities and differences: Policy and programmatic implications. Food and Nutrition Bulletin, 36(1 Suppl), S15-S23.

https://doi.org/10.1177/15648265150361S103 


\title{
Wasting and stunting-similarities and differences: Policy and programmatic implications
}

\author{
André Briend, Tanya Khara, and Carmel Dolan
}

\begin{abstract}
Wasting and stunting are often presented as two separate forms of malnutrition requiring different interventions for prevention and/or treatment. These two forms of malnutrition, however, are closely related and often occur together in the same populations and often in the same children. Wasting and stunting are both associated with increased mortality, especially when both are present in the same child. A better understanding of the pathophysiology of these two different forms of malnutrition is needed to design efficient programs. A greatly reduced muscle mass is characteristic of severe wasting, but there is indirect evidence that it also occurs in stunting. A reduced muscle mass increases the risk of death during infections and also in many other different pathological situations. Reduced muscle mass may represent a common mechanism linking wasting and stunting with increased mortality. This suggests that to decrease malnutrition-related mortality, interventions should aim at preventing both wasting and stunting, which often share common causes. Also, this suggests that treatment interventions should focus on children who are both wasted and stunted and therefore have the greatest deficits in muscle mass, instead of focusing on one or the other form of malnutrition. Interventions should also focus on young infants and children, who have a low muscle mass in relation to body weight to start with. Using mid-upper-arm circumference (MUAC) to select children in need of treatment may represent a simple way to target young wasted and stunted children efficiently
\end{abstract}

André Briend is affiliated with the Department of Nutrition, Exercise and Sports, University of Copenhagen, Denmark, and the Department for International Health, University of Tampere School of Medicine, Tampere, Finland; Tanya Khara and Carmel Dolan are affiliated with the Emergency Nutrition Network, Oxford, UK.

Please direct queries to the corresponding author: André Briend, Department of Nutrition, Exercise and Sports, University of Copenhagen, DK-1958 Frederiksberg, Denmark; e-mail: andre.briend@gmail.com. in situations where these two conditions are present. Wasting is also associated with decreased fat mass. A decreased fat mass is frequent but inconsistent in stunting. Fat secretes multiple hormones, including leptin, which may have a stimulating effect on the immune system. Depressed immunity resulting from low fat stores may also contribute to the increased mortality observed in wasting. This may represent another common mechanism linking wasting and stunting with increased mortality in situations where stunting is associated with reduced fat mass. Leptin may also have an effect on bone growth. This may explain why wasted children with low fat stores have reduced linear growth when their weight-for-height remains low. It may also explain the frequent association of stunting with previous episodes of wasting. Stunting, however, can occur in the absence of wasting and even in overweight children. Thus, food supplementation should be used with caution in populations where stunting is not associated with wasting and low fat stores.

\section{Introduction}

The terms wasting and stunting were introduced in the early 1970s by John Waterlow to differentiate, among underweight children, those who had a low weight in relation to their height (wasted) from those who were small for their age (stunted) [1-3]. Based on clinical experience, he considered that wasted children were more at risk than stunted children and that children who were both wasted and stunted were the most at risk [4].

The terms "acute" and "chronic" malnutrition are often used to describe wasting and stunting, respectively. Although it is generally true that wasting is a more transient form of malnutrition [5], these terms may be misleading. Both moderate and severe wasting, if untreated, can last several months [6,7], which does not correspond to the usual meaning of "acute." And whereas becoming stunted, i.e., having a height/ length-for-age $z$-score $<-2$, may take several months, the process of stunting, i.e., having a suboptimal linear 
growth [8], can start immediately in response to an acute stress. The term "severe acute malnutrition" (SAM), which also includes edematous malnutrition, however, is widely used and has been endorsed by a UNICEF/ World Health Organization (WHO) Joint Statement [9].

The relationship and associations between wasting and stunting are not yet well understood. Both forms of malnutrition probably share many causal pathways, as an extensive review of the literature failed to identify risk factors for wasting not associated with stunting [10]. At the population level, the frequency of stunting in the age group from 18 to 24 months is correlated with that of wasting in children less than 17 months of age [5]. These two forms of malnutrition are unquestionably linked, but the direct relationship between them has not been elaborated.

In this paper we review the similarities and differences in the pathophysiology of wasting and stunting and their relationship, and discuss the implications for programs and policy.

\section{Pathophysiology of wasting and stunting}

\section{Changes in body composition during malnutrition}

When energy intake is insufficient to sustain metabolism, different physiological adjustments take place to ensure that key organs have adequate fuel supply by drawing on the body's nutritional reserves, mainly fat and muscle [11]. If food deprivation is sustained and occurs during the growth period, animal models suggest that major changes in relative organ size take place, sparing the brain but affecting the heart, kidney, thymus, and especially the muscles, with possible longterm consequences even during adult life [12]. These adjustments follow rapid changes in insulin and glucagon levels and include both short-term and long-term regulation of key enzymes, putting the organism in an energy-sparing mode.

During acute malnutrition in the absence of infection, metabolism is sustained mainly by mobilizing fat stores, with most organs getting the energy they need from fatty acid catabolism. Most fatty acids do not cross easily the blood-brain barrier, however, and the brain usually gets most of its energy from glucose. After a few days of insufficient energy intake, the brain shifts to also using water soluble ketone bodies, which are also derived from fatty acid catabolism. This shift toward ketone bodies occurs earlier in children than in adults, presumably because of the higher relative brain mass of children, with a high glucose demand in relation to body weight. Even with the increasing use of ketone bodies, the brain (and red cells) continue to use glucose, which is produced from the glycerol derived from triglycerides, but also by the liver and kidney from amino acids (alanine and glutamine) released from muscle. Amino acids from muscle are also needed to sustain protein metabolism when protein intake is insufficient (which usually goes hand in hand with deficient energy intake). But in the absence of infection, only a minimal level of protein catabolism is required to fulfill glucose and protein needs, muscle mass loss is minimal, and the organism lives mainly on body fat stores. In this situation, death occurs when the fat reserve is exhausted [11].

During infection, there is an added double nutritional stress. First, food intake is typically reduced as a result of anorexia, and second, there is an increased demand for amino acids for the accelerated synthesis of acute phase proteins, for the production of glutathione, and for building up the adaptive immune response. These reactions to infection have a negative effect on nitrogen balance (even when dietary intake is adequate), which leads to the mobilization of amino acids from lean tissues, mainly from muscle [13].

The body's response to a range of aggression can also shed light on the body's response to restricted dietary intake and infection. Conditions as different as burns, sepsis, and cancer are also associated with the mobilization of amino acids from muscle by mechanisms that are the same as those involved in responses to insufficient energy intake and infection [14]. Inflammation can lead to the development of insulin resistance, also contributing to a reduction of nutrients available for muscle metabolism [15]. When infection or inflammation is associated with a poor-quality diet and insufficient nutrient intake, these effects reinforce each other, which leads to a rapid deterioration of muscle mass.

In summary, the metabolic adjustments taking place during malnutrition lead to a decrease in fat and muscle masses, the latter being more important when there is associated inflammation or infection. These changes in body composition, which are indirectly reflected by anthropometric indices of wasting and stunting, have important functional implications.

\section{Decreased muscle mass in wasting and stunting-a plausible common link with increased mortality}

Wasting and stunting have long been known to be associated with an increased risk of death $[16,17]$, but the mechanisms of this association are rarely discussed. Anthropometric indices of wasting and stunting measure a statistical deviation of body size from a standard. A direct link between these anthropometric indices and mortality would suppose that the organism is able to assess this deviation. However, the existence of a central "sizostat" allowing the organism to compare its current size with a theoretical value, postulated in 1963 by Tanner [18], has not been confirmed by experimental evidence and now seems very unlikely [19]. The existence of a physiological change related to this difference 
expressed in standard deviations of the growth standards seems even less plausible. Hence, z-scores for weight-for-height and height-for-age (indices of wasting and stunting, respectively) should be considered as statistical concepts with no clear link with physiological changes, and their association with mortality should be considered as indirect and noncausal.

In his early papers, Waterlow speculated that children with wasting have an alteration of body composition [1]. Forty years later, the most compelling explanation of the association of wasting and stunting with mortality is indeed that wasting and stunting reflect changes in body composition, in particular a decrease in muscle and fat mass, which, if severe, compromise the provision of fuel to vital organs, such as the heart, kidney, liver, immune system, and gut, especially when infection is also present.

In clinical settings, muscle mass is a major determinant of survival in malnourished adult patients with infections [20] and also in conditions as diverse as liver transplantation [21], liver cirrhosis [22], cancer [23, $24]$, and chronic obstructive pulmonary disease [25, 26]. Studies in these patients consistently show that those with a high muscle mass have better survival, independently of their body mass index.

Children have a lower muscle mass in relation to body weight than do adults. This effect is difficult to quantify, as muscle mass cannot be measured reliably in infants and young children, but it is undoubtedly present, as postmortem studies show that muscle mass represents only $23 \%$ of body mass in newborns, versus $43 \%$ in adults [27]. Also, in children, the brain, with its high demand for glucose, has a size in relation to body weight that is unprecedented in the history of evolution. Since a large proportion of glucose is derived from amino acids derived from muscle, an effect of low muscle mass on survival is even more likely for children than for adults. This is also suggested by epidemiological studies linking indices of muscularity at the arm level with the risk of death in contexts where the association between infection and malnutrition is a major cause of death $[28,29]$.

Despite the importance of muscle mass as a determinant of survival in the association between malnutrition and infection, and the visible muscle wasting seen in children with SAM, the decrease of muscle mass in child malnutrition has hardly been measured. Those studies which have been done took place in the 1970s. Limitations in the application of methods to measure muscle mass in children are one reason for this lack of data. Among modern methods used to measure muscle mass, imaging techniques require expensive equipment and expose children to undesirable doses of x-rays. These techniques also require that the patient remain still for a few minutes, which is difficult to obtain in young children. Segmental bioimpedance analysis, which does not rely on $\mathrm{x}$-rays, also requires the patient to remain still and so far has not been applied to young children [30].

Dilution of ${ }^{15} \mathrm{~N}$-labeled creatine, the most reliable method to measure muscle mass, has been used in only seven children with SAM compared with eight controls (often the same children) at recovery [31]. In this sample of wasted children with an average weightfor-height of $70 \%$, the muscle mass was only $49 \%$ of the level expected for their height, showing that loss of muscle mass is disproportionately high in severely wasted children. Measurement of urinary 3-methyl histidine secretion is an indirect marker of muscle mass. Its measurement in children with SAM also suggests a drastic reduction of muscle mass in relation to body weight to less than one-third of that in well-nourished children [32]. These measurements also indicate that the relationship between creatinine and 3-methyl histidine excretion is altered in children with SAM, suggesting an abnormal muscle tissue composition. This is consistent with major histological changes in muscle tissue observed in malnourished children, with a decreased proportion of myogenic cells compared with vascular, nerve, and interstitial cells [33].

There are even fewer data on the body composition and muscle mass of stunted children. Indirect evidence suggests that muscle mass is also reduced in relation to body weight in stunted children, although the absence of clinically visible muscle wasting suggests that it is less pronounced than in wasting. Muscle is located mainly in the limbs, and the muscle arm area or circumference can be considered as a proxy estimate of muscle mass. Muscle arm indices derived from mid-upper-arm circumference (MUAC) are related to height-for-age [34-36]. Arm and leg lengths are also likely to be determinants of muscle mass, and a reduced limb length may lead to decreased muscle mass in the stunted child. Both arm and leg lengths seem to be reduced in relation to total body length during stunting [37]. Epidemiological studies show that the length deficit predominates in the legs during stunting, presumably because growth retardation usually occurs during the first 2 years of life at an age where linear growth predominates in the lower part of the body [38].

The presence of low muscle mass in both wasting and stunting and the link between muscle mass and survival in a wide range of clinical conditions suggest that both wasting and stunting could increase the risk of death through a decreased muscle mass. Both conditions are associated with increased mortality, especially when they are severe: the mortality associated with severe stunting is higher than that associated with moderate wasting. The greater decrease in muscle mass associated with wasting could explain the higher risk of death associated with wasting compared with stunting (fig. 1) [17]. A common mechanism involving a reduced muscle mass (through limbs being both thinner and shorter in wasting and stunting, respectively) 


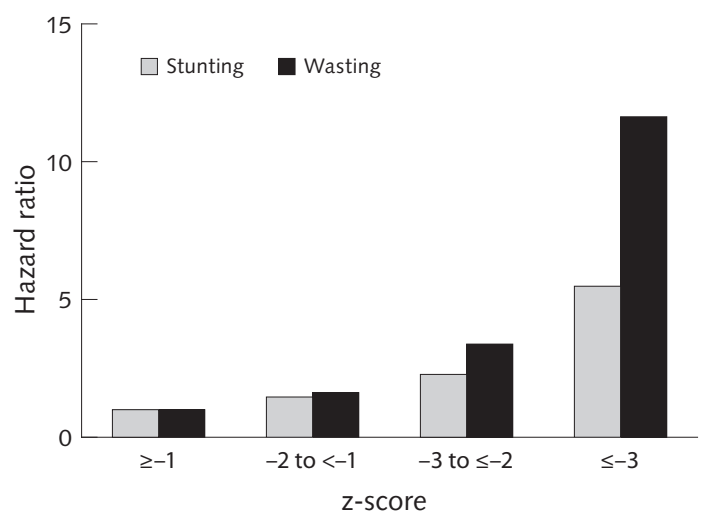

FIG. 1. Risk of death associated with wasting and stunting. The larger increase in mortality observed with wasting can be explained by the more important muscle and fat loss observed in wasting. Source: adapted from Olofin et al. [17]

would also explain why the risk of death is considerably increased when wasting and stunting are both present in the same child [39] (fig. 2). If malnutrition is sustained and is associated with changes in relative organ weights and reduced function of key organs, such as the heart, kidney, and immune system, this can also compound the effect of the lack of fuel resulting from low muscle mass during an acute food shortage.

An effect of wasting and stunting on mortality through reduced muscle mass suggests that young infants and children are especially vulnerable to

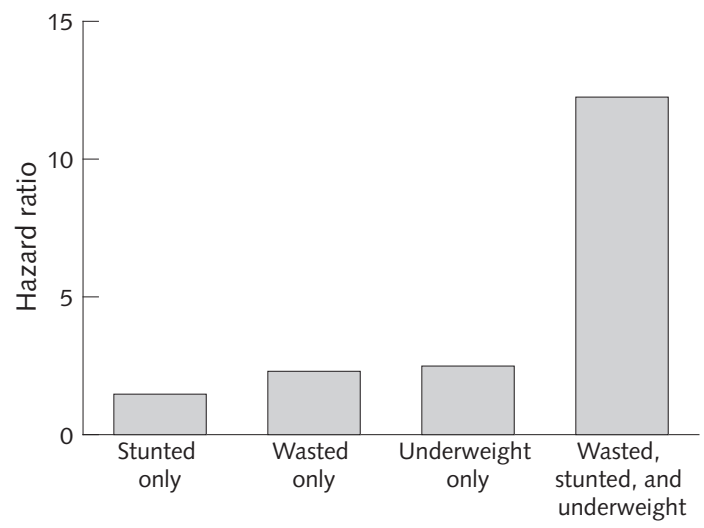

FIG. 2. Combined effects of wasting and stunting on mortality. The risk of dying increases dramatically when wasting and stunting are present at the same time. This interaction is in favor of a common mechanism linking wasting and stunting with an increased risk of death. Low muscle mass, which is present in both forms of malnutrition and known to be associated with increased mortality in a wide range of clinical conditions, could be this common mechanism. Low fat mass could be an additional effect in situations where it is associated with stunting. Source: adapted from McDonald et al. [39] malnutrition because they have a low muscle mass in relation to body weight, even in the absence of malnutrition as mentioned above.

\section{Fat mass in wasting and stunting: Effect on mortality}

Fat stores are deeply depressed in cases of wasting [3]. The effect of stunting on fat reserves is not so clear. Lower skinfold thickness or body fatness has been reported in stunted children $[36,40]$ but stunted children can also be overweight in terms of weightfor-height [41], suggesting they may also have excess body fat.

As noted above, in the absence of infection, fat is the main fuel for the organism in case of insufficient energy intake, and survival can therefore be linked to fat mass [11]. Fat, and especially central fat, can also play a role in maintaining the immune system, which is energy demanding when stimulated [42]. Leptin, which is produced by adipocytes and reflects body fat stores, may have a stimulating effect on the immune system by increasing cytokine and lymphocyte secretion [ 43 , 44]. Thus, fat can also be linked to survival through an effect on the immune system. In this regard, a recent study has shown that leptin levels are linked to survival in children with SAM treated in the hospital [45]. Thus, fat depletion could also provide an additional common mechanism linking wasting and stunting with increased mortality in situations where stunting is associated with low fat stores. A study in Senegal, however, failed to find an independent association between arm skinfold thickness and survival [28].

\section{Possible direct link between wasting and stunting}

Children with severe wasting are often stunted, suggesting that wasting and stunting have a common cause or that one form of malnutrition can contribute to the development of the other. That wasting may be a cause of stunting is supported by two studies examining the growth pattern of children recovering from SAM. The first study showed that among children with SAM who had linear catch-up growth, two-thirds started to grow only after reaching a weight-for-height of at least $85 \%$ of the National Center for Health Statistics (NCHS) median [46]. The other study indicated that during SAM treatment, linear growth accelerated as weightfor-height increased, without a clear threshold above which growth resumed [47]. Both studies suggest that growth in height takes place only when the body has a minimum of energy reserves. This is also consistent with seasonal changes in growth in height and weight, which take place at different times of the year in communities with varying food availability, where children appear to grow in height only when their weight-forheight is high at the beginning of the season $[48,49]$. A similar association between initial weight-for-height 
and growth in length in the following months, without a threshold effect, has also been reported in cohorts with a very low prevalence of wasting $[50,51]$. A recent review of the association between wasting and stunting showed that wasting after 6 months of age is associated with a lower attained length-for-age at 17 months [5].

These observations may be explained by the role of fat in regulating bone mass and linear growth [51]. Recent advances suggest that fat and bones can both be regarded as endocrine organs secreting hormones and interacting with each other and with other organs, including the brain. Fat tissues produce leptin, which has an influence on bone density and catch-up growth $[52,53]$. A study in moderately wasted children suggests that catch-up growth in length takes place only in children with a increase in leptin concentration [54]. These early findings need confirmation in children recovering from SAM and also in moderately wasted children, but they suggest that wasting associated with low fat stores and low leptin levels may halt linear growth and may prevent linear catch-up growth if untreated. Clinical observations of two children with congenital leptin deficiency and normal linear growth [55] suggest, however, that other factors beyond leptin are important in regulating linear growth.

The possible link between low fat stores, often associated with wasting, and linear growth and the existence of a plausible mechanism to explain this association do not imply that wasting is the major cause of stunting. Other mechanisms causing stunting can be involved, and high levels of stunting prevalence can be observed in populations where wasting is uncommon $[3,56]$. A recent review of eight community studies examining growth longitudinally suggests that, despite the link between periods of wasting and subsequent stunting, stunting is far more common than the prevalence of earlier wasting can explain [5]. Also, low birthweight explains part of stunting prevalence independently of wasting [57].

The long-term effect on stunting of repeated episodes of weight loss has also been extensively examined in the context of repeated episodes of diarrhea. The available evidence suggests that in these children, weight loss related to diarrheal episodes is transient and is followed by catch-up growth, and that its long-term effect on linear growth explains only a small part of the observed stunting [58]. A link between environmental enteropathy and linear growth, however, seems plausible [59].

Stunting can coexist with a high overweight prevalence in some populations [41]. This suggests that if high fat stores are needed to promote linear growth, they are not sufficient. Sulfur, phosphorus, calcium, magnesium, vitamins $\mathrm{D}, \mathrm{K}$, and $\mathrm{C}$, and copper are nutrients that are required in higher amounts for skeletal growth than for growth of other lean tissues [60]. Insufficient intake of these nutrients may explain a high prevalence of stunting in the absence of wasting. A low intake of nutrients needed for bone growth and lean tissue synthesis may explain the possible association of stunting with reduced muscle mass and normal or even increased fat reserves. This possible mechanism is supported by the observation that diets with insufficient zinc content are associated with low height gains and excess fat deposition during catch-up growth of children with SAM [61].

\section{Policy and programmatic implications of the similarities and interactions between wasting and stunting}

Interventions should be targeted as a priority to children who have a high risk of death and also to those who have a high probability of responding to treatment. Accepting that wasting and stunting increase the risk of death through common mechanisms and are interrelated has implications for selecting interventions based on these two criteria. This suggests that there is no strong rationale for different interventions for these two forms of malnutrition, except in situations where stunting occurs in the absence of wasting and is associated with normal fat stores.

\section{Selecting children at high risk}

Considering wasting and stunting as two separate conditions can lead to misguided decisions, as this approach neglects the fact that they can occur simultaneously in the same individual and that there are important interactions between these two conditions. In particular, focusing interventions to reduce mortality on wasted children on the assumption that they have an "acute" malnutrition will miss quite a few severely stunted children who have a higher risk of death than do moderately wasted children. Accepting common mechanisms for the association between wasting and stunting and the increased risk of death suggests that the correct approach would be not to just select children who are wasted or stunted for intervention, but to prioritize those who are both wasted and stunted.

If low muscle mass is the main common factor increasing the risk of death in wasted and stunted children with associated infections, age should also be considered as an additional risk factor, as muscle mass is proportionally lower in younger children. Selecting young wasted and stunted children may seem a challenge, as this implies combining with adequate weighting factors two indices that themselves are composite variables (weight-for-height and height-for-age), with an additional unknown correction factor related to age to take into account the lower muscle mass of young children. This objective, however, is likely to be achieved in a simple way by using MUAC unadjusted 
for age as the admission criterion for treatment programs, an approach that is currently endorsed by WHO [9] and that in fact does select young children with a low weight-for-height and a low height-for-age with the highest risk of death [62-64]. Correction of MUAC for age or height does not improve the estimation of the risk of death $[65,66]$. The limited current evidence suggests that MUAC is at least as good as weight-forheight and height-for-age for estimating muscle and fat mass in relation to body weight in children [67]. Children with low MUAC should be the priority target, independently of their respective degree of wasting or stunting as defined by their weight-for-height and height-for-age.

The effect of young age on muscle mass suggests also that malnourished children under 6 months of age, particularly children born small for gestational age, who are often neglected in current programs, should be a primary target of programs aiming at preventing death.

\section{Identifying children who will benefit from interventions}

\section{Preventive interventions}

The immediate underlying and basic causes of malnutrition seem to be common to both wasting and stunting [10]. Accepting that wasting and stunting act through a common mechanism suggests that any intervention that is designed to have an effect on one form of malnutrition should also have an effect on the mortality risk associated with the other. Thus, there is a clear rationale for designing and implementing programs to simultaneously prevent both forms of malnutrition in those regions and countries (the majority) where both wasting and stunting are prevalent.

In contexts where stunting exists in the absence of wasting, and more specifically when stunting is not associated with low body fat stores, programs aiming specifically at stunted children are warranted. Arguably, this is the only situation where separating these two forms of malnutrition has a strong rationale. Food supplementation programs should be used carefully in these situations because they may increase the prevalence of overweight if given indiscriminately [68]. The food supplements, where used, should be carefully formulated to ensure that key nutrients for lean tissue synthesis and bone growth are included to avoid excess fat deposition [60].

\section{Therapeutic intervention}

There is ample evidence that wasted children put on weight (mainly muscle and fat) very rapidly when fed an adequate energy- and nutrient-dense diet and infection is treated $[3,69,70]$. Assuming that low muscle and fat mass increases the risk of death, current treatment is likely to highly benefit wasted children.

Treatment of wasting with ready-to-use therapeutic food (RUTF) has a limited effect on stunting during the catch-up phase [71]. The increase in muscle mass obtained by treating the associated wasting should, however, benefit stunted children, assuming that the reduced muscle mass is the main risk factor increasing mortality in stunted children.

The low fat mass observed in wasted children and in some stunted children also suggests that the increase in fat mass taking place when associated wasting is corrected will potentially benefit stunted children who have a low fat mass to start with. This will result in an increased hormone production from adipocytes, in particular of leptin, which will stimulate immunity and linear growth.

\section{Research gaps}

The relationship between wasting and stunting and their functional consequences is still poorly understood. Although a coherent plausible picture emerges from our current knowledge, there remain evidence gaps and mechanisms that require confirmation.

» Changes in body composition, in particular in muscle mass and fat mass, and their relationship to anthropometric indicators and functional outcomes should be better explored in wasted and stunted children.

» The relationship between fat stores and stunting and the possible role of leptin should be explored. This should help to clarify the need to increase energy intake in stunted populations, finding the balance between ensuring a minimum fat store to promote linear growth and avoiding giving too much energy and thus exposing children to the risk of becoming overweight.

» Response to treatment, and in particular changes in height and body composition in response to supplementation in wasted and stunted children, should be better described.

" In high-burden contexts, case studies are needed where joint wasting and stunting prevention and linked treatment programs are implemented. These should explore the policy and programmatic lessons from linking wasting and stunting and, in particular, clear monitoring of outcomes.

\section{Acknowledgments}

The authors thank Carlos Grijalva-Eternod for his comments and discussion during the preparation of the manuscript. 


\section{References}

1. Waterlow JC. Classification and definition of proteincalorie malnutrition. Br Med J 1972;3:566-9.

2. Waterlow JC. Note on the assessment and classification of protein-energy malnutrition in children. Lancet 1973;2:87-9.

3. Waterlow JC. Protein energy malnutrition. London: Edward Arnold, 1992.

4. Waterlow JC. Some aspects of childhood malnutrition as a public health problem. Br Med J 1974;4:88-90.

5. Richard SA, Black RE, Gilman RH, Guerrant RL, Kang G, Lanata CF, Mølbak K, Rasmussen ZA, Sack RB, Valentiner-Branth P, Checkley W; Childhood Infection and Malnutrition Network. Wasting is associated with stunting in early childhood. J Nutr 2012;142:1291-6.

6. Garenne M, Willie D, Maire B, Fontaine O, Eeckels R, Briend A, Van den Broeck J. Incidence and duration of severe wasting in two African populations. Public Health Nutr 2009;12:1974-82.

7. Isanaka S, Grais RF, Briend A, Checchi F. Estimates of the duration of untreated acute malnutrition in children from Niger. Am J Epidemiol 2011;173:932-40.

8. Golden MH. Is complete catch-up possible for stunted malnourished children? Eur J Clin Nutr 1994;48(suppl 1):S58-70; discussion S71.

9. World Health Organization. WHO child growth standards and the identification of severe acute malnutrition in infants and children: joint statement by the World Health Organization and the United Nations Children's Fund. Geneva and New York: WHO and UNICEF, 2009.

10. Martorell R, Young MF. Patterns of stunting and wasting: Potential explanatory factors. Adv Nutr 2012;3:227-33.

11. Cahill GF Jr. Fuel metabolism in starvation. Annu Rev Nutr 2006;26:1-22.

12. Desai M, Crowther NJ, Lucas A, Hales CN. Organselective growth in the offspring of protein-restricted mothers. Br J Nutr 1996;76:591-603.

13. Reeds PJ, Fjeld CR, Jahoor F. Do the differences between the amino acid compositions of acute-phase and muscle proteins have a bearing on nitrogen loss in traumatic states? J Nutr 1994;124:906-10.

14. Lecker SH, Solomon V, Mitch WE, Goldberg AL. Muscle protein breakdown and the critical role of the ubiquitinproteasome pathway in normal and disease states. J Nutr 1999;129:227S-37S.

15. Fernández-Real JM, Ricart W. Insulin resistance and inflammation in an evolutionary perspective: the contribution of cytokine genotype/phenotype to thriftiness. Diabetologia 1999;42:1367-74.

16. Caulfield LE, de Onis M, Blössner M, Black RE. Undernutrition as an underlying cause of child deaths associated with diarrhea, pneumonia, malaria, and measles. Am J Clin Nutr 2004;80:193-8.

17. Olofin I, McDonald CM, Ezzati M, Flaxman S, Black RE, Fawzi WW, Caulfield LE, Danaei G. Associations of suboptimal growth with all-cause and cause-specific mortality in children under five years: a pooled analysis of ten prospective studies. PloS One 2013;8:e64636.

18. Tanner JM. Regulation of growth in size in mammals. Nature 1963;199:845-50.

19. Finkielstain GP, Lui JC, Baron J. Catch-up growth: cellular and molecular mechanisms. World Rev Nutr Diet 2013;106:100-4.

20. Wolfe RR. The underappreciated role of muscle in health and disease. Am J Clin Nutr 2006;84:475-82.

21. Tandon P, Ney M, Irwin I, Ma MM, Gramlich L, Bain VG, Esfandiari N, Baracos V, Montano-Loza AJ, Myers RP. Severe muscle depletion in patients on the liver transplant wait list: its prevalence and independent prognostic value. Liver Transpl 2012;18:1209-16.

22. Montano-Loza AJ, Meza-Junco J, Prado CMM, Lieffers JR, Baracos VE, Bain VG, Sawyer MB. Muscle wasting is associated with mortality in patients with cirrhosis. Clin Gastroenterol Hepatol 2012;10:166-73, 173.e1.

23. Gonzalez MC, Pastore CA, Orlandi SP, Heymsfield SB. Obesity paradox in cancer: new insights provided by body composition. Am J Clin Nutr 2014; 99:999-1005.

24. Heymsfield SB, McManus C, Stevens V, Smith J. Muscle mass: reliable indicator of protein-energy malnutrition severity and outcome. Am J Clin Nutr 1982;35:1192-9.

25. Marquis K, Debigaré R, Lacasse Y, LeBlanc P, Jobin J, Carrier G, Maltais F. Midthigh muscle cross-sectional area is a better predictor of mortality than body mass index in patients with chronic obstructive pulmonary disease. Am J Respir Crit Care Med 2002;166:809-13.

26. Soler-Cataluña JJ, Sánchez-Sánchez L, Martínez-García MA, Sánchez PR, Salcedo E, Navarro M. Mid-arm muscle area is a better predictor of mortality than body mass index in COPD. Chest 2005;128:2108-15.

27. Food and Agriculture Organization/World Health Organization/United Nations University. Energy and protein requirements. Report of a joint $\mathrm{FAO} / \mathrm{WHO} /$ UNU Expert Consultation. World Health Organ Tech Rep Ser 1985;724:1-206.

28. Briend A, Garenne M, Maire B, Fontaine O, Dieng K. Nutritional status, age and survival: the muscle mass hypothesis. Eur J Clin Nutr 1989;43:715-26.

29. Van den Broeck J, Eeckels R, Hokken-Koelega A. Fatness and muscularity as risk indicators of child mortality in rural Congo. Int J Epidemiol 1998;27:840-4.

30. McCarthy HD, Samani-Radia D, Jebb SA, Prentice AM. Skeletal muscle mass reference curves for children and adolescents. Pediatr Obes 2014;9:249-59.

31. Reeds PJ, Jackson AA, Picou D, Poulter N. Muscle mass and composition in malnourished infants and children and changes seen after recovery. Pediatr Res 1978;12:613-8.

32. Nagabhushan VS, Narasinga Rao BS. Studies on 3-methylhistidine metabolism in children with proteinenergy malnutrition. Am J Clin Nutr 1978;31:1322-7.

33. Hansen-Smith FM, Picou D, Golden MN. Quantitative analysis of nuclear population in muscle from malnourished and recovered children. Pediatr Res 1978;12:167-70.

34. Frisancho AR, Garn SM. Skin-fold thickness and muscle size: Implications for developmental status and nutritional evaluation of children from Honduras. Am J Clin Nutr 1971;24:541-6.

35. Friedman JF, Phillips-Howard PA, Mirel LB, Terlouw DJ, Okello N, Vulule JM, Hawley WA, Nahlen BL, ter Kuile F. Progression of stunting and its predictors among 
school-aged children in western Kenya. Eur J Clin Nutr 2005;59:914-22.

36. Tanner S, Leonard WR, Reyes-García V; TAPS Bolivia Study Team. The consequences of linear growth stunting: influence on body composition among youth in the Bolivian Amazon. Am J Phys Anthropol 2014;153:92-102.

37. Pomeroy E, Stock JT, Stanojevic S, Miranda JJ, Cole TJ, Wells JCK. Trade-offs in relative limb length among Peruvian children: extending the thrifty phenotype hypothesis to limb proportions. PloS One 2012;7:e51795.

38. Bogin B, Varela-Silva MI. Leg length, body proportion, and health: a review with a note on beauty. Int J Environ Res Public Health 2010;7:1047-75.

39. McDonald CM, Olofin I, Flaxman S, Fawzi WW, Spiegelman D, Caulfield LE, Black RE, Ezzati M, Danaei G. The effect of multiple anthropometric deficits on child mortality: meta-analysis of individual data in 10 prospective studies from developing countries. Am J Clin Nutr 2013;97:896-901.

40. Walker SP, Grantham-McGregor S, Powell C, Fletcher P, Himes JH. Bioelectrical impedance, anthropometry and body composition in stunted and non-stunted children. Eur J Clin Nutr 1990;44:763-8.

41. Popkin BM, Richards MK, Montiero CA. Stunting is associated with overweight in children of four nations that are undergoing the nutrition transition. J Nutr 1996;126:3009-16.

42. Wells JCK, Cortina-Borja M. Different associations of subscapular and triceps skinfold thicknesses with pathogen load: an ecogeographical analysis. Am J Hum Biol 2013;25:594-605.

43. Fernández-Riejos P, Najib S, Santos-Alvarez J, MartínRomero C, Pérez-Pérez A, González-Yanes C, SánchezMargalet V. Role of leptin in the activation of immune cells. Mediators Inflamm 2010;2010:568343.

44. Martín-Romero C, Santos-Alvarez J, Goberna R, Sánchez-Margalet V. Human leptin enhances activation and proliferation of human circulating $\mathrm{T}$ lymphocytes. Cell Immunol 2000;199:15-24.

45. Bartz S, Mody A, Hornik C, Bain J, Muehlbauer M, Kiyimba T, Kiboneka E, Stevens R, Bartlett J, St Peter JV, Newgard CB, Freemark M. Severe acute malnutrition in childhood: hormonal and metabolic status at presentation, response to treatment, and predictors of mortality. J Clin Endocrinol Metab 2014;99:2128-37.

46. Walker SP, Golden MH. Growth in length of children recovering from severe malnutrition. Eur J Clin Nutr 1988;42:395-404.

47. Doherty CP, Sarkar MA, Shakur MS, Ling SC, Elton RA, Cutting WA. Linear and knemometric growth in the early phase of rehabilitation from severe malnutrition. Br J Nutr 2001;85:755-9.

48. Brown KH, Black RE, Becker S. Seasonal changes in nutritional status and the prevalence of malnutrition in a longitudinal study of young children in rural Bangladesh. Am J Clin Nutr 1982;36:303-13.

49. Maleta K, Virtanen SM, Espo M, Kulmala T, Ashorn P. Seasonality of growth and the relationship between weight and height gain in children under three years of age in rural Malawi. Acta Paediatr 2003;92:491-7.

50. Xu X, Wang WP, Guo ZP, Cheung YB, Karlberg J. Seasonality of growth in Shanghai infants $(n=4128)$ born in 11 consecutive years. Eur J Clin Nutr 2001;55:714-25.
51. Dewey KG, Hawck MG, Brown KH, Lartey A, Cohen RJ, Peerson JM. Infant weight-for-length is positively associated with subsequent linear growth across four different populations. Matern Child Nutr 2005;1:11-20.

52. Karsenty G. Convergence between bone and energy homeostases: leptin regulation of bone mass. Cell Metab 2006;4:341-8.

53. Gat-Yablonski G, Ben-Ari T, Shtaif B, Potievsky O, Moran O, Eshet R, Maor G, Segev Y, Phillip M. Leptin reverses the inhibitory effect of caloric restriction on longitudinal growth. Endocrinology 2004;145:343-50.

54. Büyükgebiz B, Oztürk Y, Yilmaz S, Arslan N. Serum leptin concentrations in children with mild proteinenergy malnutrition and catch-up growth. Pediatr Int 2004;46:534-8.

55. Montague CT, Farooqi IS, Whitehead JP, Soos MA, Rau H, Wareham NJ, Sewter CP, Digby JE, Mohammed SN, Hurst JA, Cheetham CH, Earley AR, Barnett AH, Prins JB, O'Rahilly S. Congenital leptin deficiency is associated with severe early-onset obesity in humans. Nature 1997;387:903-8.

56. Chotard S, Mason JB, Oliphant NP, Mebrahtu S, Hailey $\mathrm{P}$. Fluctuations in wasting in vulnerable child populations in the Greater Horn of Africa. Food Nutr Bull 2010;31:S219-33.

57. Christian P, Lee SE, Donahue Angel M, Adair LS, Arifeen SE, Ashorn P, Barros FC, Fall CH, Fawzi WW, Hao W, Hu G, Humphrey JH, Huybregts L, Joglekar CV, Kariuki SK, Kolsteren P, Krishnaveni GV, Liu E, Martorell R, Osrin D, Persson LA, Ramakrishnan U, Richter L, Roberfroid D, Sania A, Ter Kuile FO, Tielsch J, Victora CG, Yajnik CS, Yan H, Zeng L, Black RE. Risk of childhood undernutrition related to small-for-gestational age and preterm birth in low- and middle-income countries. Int J Epidemiol 2013;42:1340-55.

58. Richard SA, Black RE, Gilman RH, Guerrant RL, Kang G, Lanata CF, Mølbak K, Rasmussen ZA, Sack RB, Valentiner-Branth P, Checkley W. Diarrhea in early childhood: short-term association with weight and long-term association with length. Am J Epidemiol 2013;178:1129-38.

59. Humphrey JH. Child undernutrition, tropical enteropathy, toilets, and handwashing. Lancet 2009;374:1032-5.

60. Golden MH. Proposed recommended nutrient densities for moderately malnourished children. Food Nutr Bull 2009;30:S267-342.

61. Golden MH, Golden BE. Effect of zinc supplementation on the dietary intake, rate of weight gain, and energy cost of tissue deposition in children recovering from severe malnutrition. Am J Clin Nutr 1981;34:900-8.

62. Berkley J, Mwangi I, Griffiths K, Ahmed I, Mithwani S, English M, Newton C, Maitland K. Assessment of severe malnutrition among hospitalized children in rural Kenya: comparison of weight for height and mid upper arm circumference. JAMA 2005;294:591-7.

63. Myatt M, Khara T, Collins S. A review of methods to detect cases of severely malnourished children in the community for their admission into communitybased therapeutic care programs. Food Nutr Bull 2006;27:S7-23.

64. Khara T, Dolan C. Technical Briefing Paper. The relationship between wasting and stunting, policy, programming and research implications. Emergency Nutrition 
Network and US Agency for International Development. June 2014. Available at: http://files.ennonline .net/attachments/1862/WAST_140714.pdf. Accessed 5 November 2014.

65. Briend A, Zimicki S. Validation of arm circumference as an indicator of risk of death in one to four year old children. Nutr Res 1986;6:249-61.

66. Rasmussen J, Andersen A, Fisker AB, Ravn H, Sodemann M, Rodrigues A, Benn CS, Aaby P. Mid-upperarm-circumference and mid-upper-arm circumference Z-score: the best predictor of mortality? Eur J Clin Nutr 2012;66:998-1003.

67. Jensen SM, Mølgaard C, Ejlerskov KT, Christensen LB, Michaelsen KF, Briend A. Validity of anthropometric measurements to assess body composition, including muscle mass, in 3-year-old children from the SKOT cohort. Matern Child Nutr 2012;8:130-133.

68. Uauy R, Kain J. The epidemiological transition: need to incorporate obesity prevention into nutrition programmes. Public Health Nutr 2002;5:223-9.

69. Ashworth A, Millward DJ. Catch-up growth in children. Nutr Rev 1986;44:157-63.

70. Golden MH. Protein-energy interactions in the management of severe malnutrition. Clin Nutr 1997;16(suppl 1): 19-23.

71. Kerac M, Bunn J, Chagaluka G, Bahwere P, Tomkins A, Collins S, Seal A. Follow-up of post-discharge growth and mortality after treatment for severe acute malnutrition (FuSAM Study): a prospective cohort study. PloS One 2014;9:e96030. 